\title{
First report on the reproduction of captive Chinese many-toothed snake (Sibynophis chinensis) in Jeju Island, South Korea
}

\author{
Maniram Banjade ${ }^{1}$, Young-Hun Jeong ${ }^{1}$, Sang-Hyun Han², Yoo-Kyung Kim', Byung Soo Kim³ and Hong-Shik Oh${ }^{4 *}$
}

\begin{abstract}
The Chinese many-toothed snake (Sibynophis chinensis) is an endangered species in South Korea. To determine its reproductive activity, here we captured a gravid S. chinensis from Mulyeongari Oreum Wetland Conservation Area, Jeju Island, on May 27, 2018, and reared it at Animal Taxonomy and Morphology Laboratory, Jeju National University, South Korea. The snake oviposited a clutch of six eggs between June 12 and 20, 2018, with an average size of $24.86 \pm 1.36 \mathrm{~mm}$ in length and $9.86 \pm 0.49 \mathrm{~mm}$ in width, which were artificially incubated at a constant temperature of $27^{\circ} \mathrm{C}$. After incubating for 34-41 days, five of these six eggs successfully hatched. Average snoutvent length (SVL), tail length (TL), and body weight (BW) of hatchlings were $136.5 \pm 5.17 \mathrm{~mm}, 47.76 \pm 2.80 \mathrm{~mm}$, and $1.66 \pm 0.12 \mathrm{~g}$, respectively. This study observed the reproductive activity of $\mathrm{S}$. chinensis and characterized its eggs and hatchlings for the first time, providing valuable information for the long-term conservation plan of $\mathrm{S}$. chinensis in South Korea.
\end{abstract}

Keywords: Clutch size, Egg characteristics, Egg-laying, Hatchling, Sibynophis chinensis

\section{Background}

The Chinese many-toothed (Sibynophis chinensis) is a non-venomous serpent native to Jeju Island in South Korea. Its ecology and biology have been poorly documented due to its small population size, limited distribution, and lack of study (NIBR 2011). S. chinensis was first documented by Gunther in 1889. It has been reported to be distributed in southern China, Taiwan, Vietnam, Laos, and Jeju Island of South Korea (Gunther 1889; IUCN 2014). In Korea, it is mainly found in lowlands with higher precipitation, very close to human activity (Kim and Oh 2005; Koo et al. 2018a; Koo et al. 2018b).

S. chinensis has a black head with a black stripe running up the dorsal neck to the back of the head. Its body scales are smooth with brighter red on its dorsal side and brilliant white on its ventral. Initially, it was described as Sibynophis collaris Paik (1982), but Kim and

\footnotetext{
* Correspondence: sciedu@jejunu.ac.kr

${ }^{4}$ Interdisciplinary Graduate Programme in Advance Convergence Technology and Science, Faculty of Science Education, Jeju National University, Jeju 6324, South Korea

Full list of author information is available at the end of the article
}

Oh (2006) reviewed its taxonomy based on the number and shape of supralabial scales and the number of anterior temporal scales and finally reported it as S. chinensis. Several studies have reported its habitat and distribution (Kim and Oh 2005), evolution (Oh et al. 2015), breeding behavior (Koo et al. 2018a), and habitat prediction (Koo et al. 2018b); however, its reproductive biology remains unknown. We provide data on morphology of eggs, clutch size, incubation period, and hatchlings size of $S$. chinensis under captive condition. The present study will be the first contribution to the reproductive biology. It will help us maintain its captive populations that can ultimately raise the category of this endangered species in this country.

\section{Methods}

Snake capture and raising

A gravid snake (Fig. 1a) was spotted accidentally and hand captured (using gloves) in Mulyeongari-oreum ("Oreum" = hills of Jeju Island) Wetland Conservation

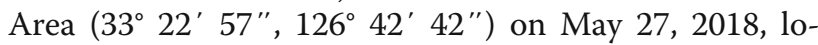
cated in Jeju Island, South Korea. It is a Ramsar site designated in 2006 (MOE 2009. The snake was measured to 

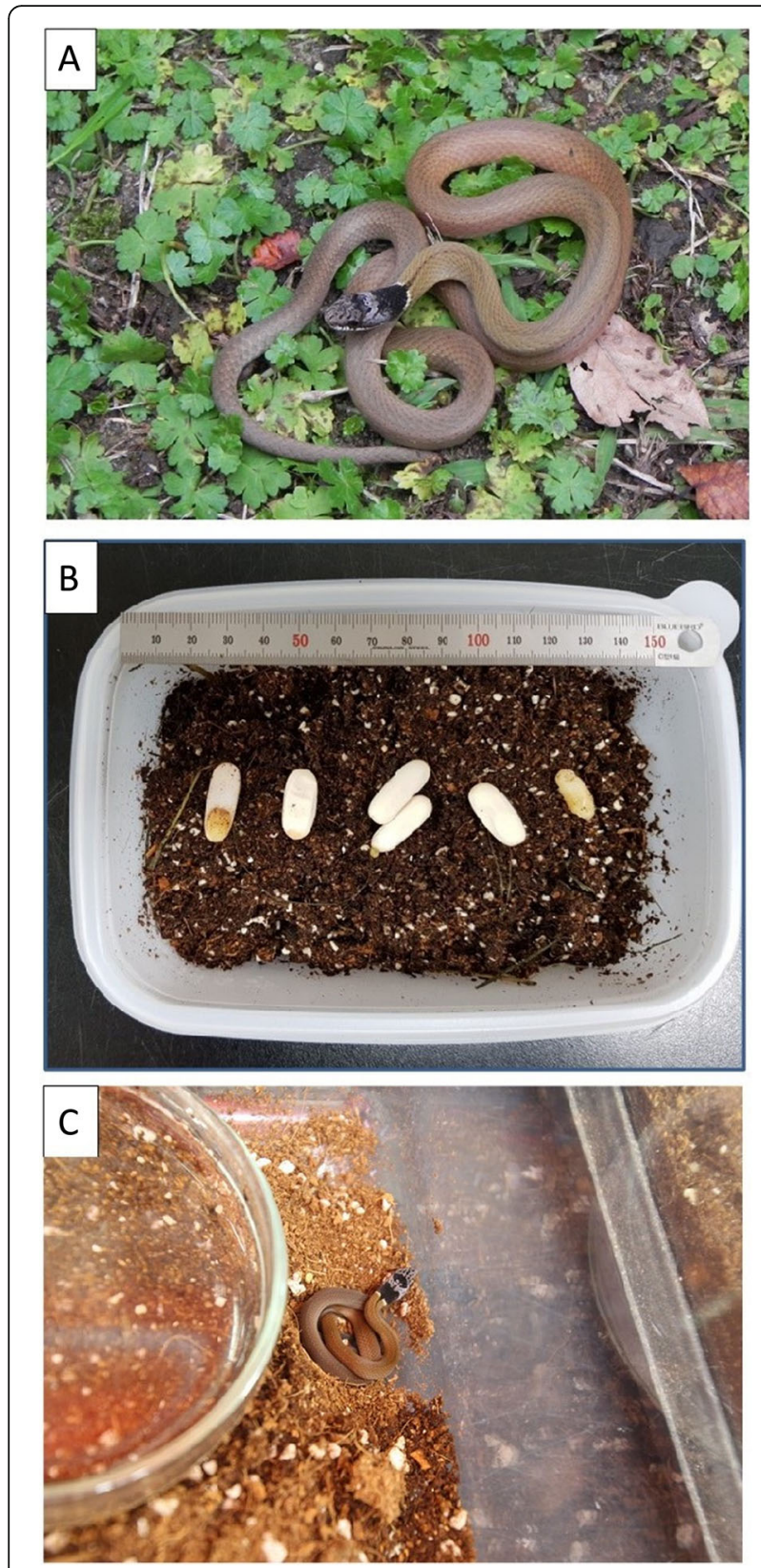

Fig. 1 a A gravid female S. chinensis from Mulyeongari oreum, Jeju Island. b A clutch containing six eggs. c Neonate of S. chinensis (housed individually in a glass cage)

have a snout-vent length (SVL) of $460 \mathrm{~mm}$, a tail length (TL) of $176 \mathrm{~mm}$, a head length (HL) of $15.70 \mathrm{~mm}$, and a body weight (BW) of $44.8 \mathrm{~g}$. It was carried to the Animal Taxonomy and Morphology Laboratory of Jeju National University and kept inside a glasshouse $(45 \times 53 \times 45$ $\mathrm{cm}^{3}$ ). It was provided rocks and wooden logs. An ambient temperature was maintained using a heat lamp (CE 220-230 V, China) (temperature range 18 to $24^{\circ} \mathrm{C}$ ). Salamanders (Hynobius spp.) and grass lizard (Takydromus wolteri) (weight approx. 68-84g) were offered as diet once every 3-4 days. Servicing of the glasshouse consisted of removing fecal matter, providing water daily, and spraying with water to maintain humidity to be around $70-90 \%$. The snake was observed to drink from water bowls of $8 \mathrm{~cm}$ in diameter filled to $5 \mathrm{~cm}$ in depth. In addition, rocks and wooden logs facilitated the shedding of its skin.

\section{Morphology measurement}

The gravid female was inspected regularly until oviposition. Shortly after oviposition, we weighted the body mass and eggs using an electronic balance (Quintix 3102-1SKR, Germany) of $0.1 \mathrm{~g}$ precision and simultaneously measured the width and length of eggs using a digital caliper CD-15CPX (Mitutoyo, Monotoro, Japan) with $0.1 \mathrm{~mm}$ precision. Eggs were separated from the mother and incubated in an automatic incubator (Green $30 \mathrm{~m}$, Seoul, Korea) with temperature maintained at $25-28^{\circ} \mathrm{C}$ and humidity at $70-92 \%$. Within $34-41$ days of incubation, eggs hatched out. Hatchlings were kept separately in plastic boxes $29 \times 14 \times 23 \mathrm{~cm}^{3}$ with a bottom heating. Each box had a small water bowl together with pebbles, leaf litters, and branches to provide a relatively natural environment. These maintenance conditions were similar to those of adult snakes. Mealworms (Tenebrio molitor) were offered once every 2-3 days which they refused to feed. The interval between hatching and the first molt of hatchlings was 7-9 days. After complete molting, external morphologies of hatchlings including snout-vent length (SVL), tail length (TL), head length (HL), head width (HW), and the body weight (BW) were measured (Table 1). No attempt was made for sex determination due to the lack of skilled person for sex detection at juvenile stage. Finally, on August 6, 2018, 11 days after hatching, all hatchlings and their mother were released to the place from where the mother was previously captured.

\section{Result and discussion}

Eggs of S. chinensis were white, elliptical, elongated, and non-adhesive, having soft flexible shell except the last laid egg which appeared infertile because of its atypical wet appearance and semi-transparent yellowish coloration (Fig. 1b). Average length, width, and weight of egg were $24.86 \pm 1.36 \mathrm{~mm}, 9.86 \pm 0.49 \mathrm{~mm}$, and $1.43 \pm 0.15$ $\mathrm{g}$, respectively (Table 1 ). Due to the absence of peerreviewed published data on the reproductive behavior of S. chinensis, we compared eggs and clutch size with species using similar habitats. Oxyrhopus clathratus and Xylophis perroteti laid larger eggs with length of $37 \pm$ $6.2 \mathrm{~mm}$ to width of $19.5 \pm 2.5 \mathrm{~mm}$ (Maia and TravagliaCardoso 2017) and length of $31 \pm 3.4 \mathrm{~mm}$ and width of $12.6 \pm 1.3 \mathrm{~mm}$ (Santoshkumar and Kannan 2016) compared to $S$. chinensis. These studies reported that $O$. 
Table 1 Data on egg and newborns of Sibynophis chinensis biometrics

\begin{tabular}{|c|c|c|c|c|c|c|c|c|c|c|}
\hline \multirow[t]{2}{*}{ Individual ID } & \multicolumn{5}{|l|}{ Traits of egg } & \multicolumn{5}{|c|}{ Traits of newborn } \\
\hline & $\overline{E L}(\mathrm{~mm})$ & EW (mm) & WE (g) & IP (days) & $\mathrm{HD}(\min )$ & $\overline{S V L}(\mathrm{~mm})$ & $\mathrm{TL}(\mathrm{mm})$ & $\mathrm{HL}(\mathrm{mm})$ & $\mathrm{HW}(\mathrm{mm})$ & BW (g) \\
\hline BBR01 & 28.16 & 9.12 & 1.6 & 41 & 240 & 122 & 46 & 9.42 & 4.97 & 1.7 \\
\hline BBRO2 & 25.04 & 11.52 & 1.6 & 34 & 180 & 142 & 45.6 & 10.03 & 5.08 & 1.8 \\
\hline BBR03 & 27.36 & 10.27 & 1.6 & 34 & 180 & 152 & 58 & 10.02 & 4.14 & 2.03 \\
\hline BBR04 & 25.10 & 9.58 & 1.6 & 35 & 240 & 137.2 & 41.1 & 10.01 & 4.71 & 1.3 \\
\hline BBR05 & 24.86 & 10.60 & 1.6 & 36 & 270 & 129.3 & 48.1 & 9.8 & 4.91 & 1.5 \\
\hline $\mathrm{BBR}^{*} 6^{*}$ & 18.69 & 8.07 & 0.6 & n.d. & n.d. & n.d. & n.d. & n.d. & n.d. & n.d. \\
\hline Mean \pm S.E. ${ }^{* *}$ & $24.86 \pm 1.36$ & $9.86 \pm 0.49$ & $1.43 \pm 0.15$ & $36 \pm 1.3$ & $222 \pm 18$ & $136.5 \pm 5.17$ & $47.76 \pm 2.80$ & $9.85 \pm 0.12$ & $4.76 \pm 0.18$ & $1.66 \pm 0.12$ \\
\hline
\end{tabular}

$E L$ egg length, EW egg width, WE weight of egg, IP incubation period from eggs laying to time when the neonates begin to slit the shell, $H D$ hatching duration

${ }^{*}$ n.d. represents no data, this egg did not hatch (probably infertile egg)

**Mean and S.E. from only 5 individuals, except the first three columns

clathratus laid a clutch of 10-11 eggs and X. perroteti laid a clutch of 7-10 eggs, larger than the clutch size of S. chinensis (i.e., six). The clutch size of S. chinensis was similar to the clutch size of Sibynophis subpunctatus (Whitaker et al. 2004). The smaller clutch size and eggs size of S. chinensis could be due to its smaller body size compared to other species. The clutch size and egg size are known to depend on maternal characteristics such as body size and age (Roff 1992; Paterna 2017)

After 34 days of incubation, eggs began to hatch, although one egg remained unfertilized. The hatching process took an average of $222 \pm 18$ min to fully emergence from slitting eggshell. The body color of hatchling was brownish at the anterior region and grey at the posterior region (Fig. 1c). A distinct black-colored middorsal line was present from the head to the tail region. The mid-dorsal line was dense at the anterior region and faint at the posterior region. The color morphology was similar to that of the mother, although hatchlings were brighter compared to their mother. The head was triangular with two rounded black eyes. The white ring was present at the lower part of the head.

When the incubation period and hatchling size of $S$. chinensis were compared to those of related species, Gonyosoma boulengeri and Ptyas korros had longer incubation period of 52-57 days (Kane et al. 2017) and 55 days (Dieckmann et al. 2014) for their eggs compared to S. chinensis (34-41 days, this study). G. boulengeri and $P$. korros also had large hatchling sizes (7.75-10.5 g and 6$8 \mathrm{~g}$, respectively) compared to hatchlings of $S$. chinensis $1.3-2.03 \mathrm{~g}$ in this study). The short incubation time of $S$. chinensis could be due to the relatively small weight of hatchlings compared to G. boulengeri and P. korros. In general, difference in habitation and environmental condition may induce different morphological features of different species (Seebacher et al. 2016). The S. chinensis found in Jeju Island inhabits in a subtropical region, which is one of the coldest areas of Sibynophis habitats. Due to the relatively long winter seasons, its annual activation time is shorter than those of tropical snakes, which might have affected its morphological and ecological characteristics including hatchling size and incubation period.

Our observation revealed that the female of $S$. chinensis oviposits at mid-June and hatched out at the end of July (i.e., summer season). Marques and Pizzatto (2002), Lin et al. (2012), and SantoshKumar and Kannan (2016) have reported similar patterns of egg laying and hatching of Oxyrhopus guibei, P. korros, and Xylophis perroteti, respectively. This captive egg laying in summer might be the result of two mating seasons (i.e., autumn and spring). Koo et al. (2018a) have observed group mating between one female and three males in autumn. From this evidence, we hypothesized that the sperm received in autumn mating could be stored in the oviduct and remained viable during winter dormancy period. In early spring, sperms are expelled out from the oviduct to fertilize with oocyte shortly after subsequent spring mating. Many reports have explained that reptiles have two distinct mating seasons prior to ovulation, e.g., Thamnophis sirtalis in Michigan, Bothrops neuwiedi in Brazil, and Crotalus atrox in Arizona (Schwartz et al. 1989; Hartmann et al. 2004; Clark et al. 2014). Fertilization in spring ensures that eggs are laid in the middle of rainy seasons. Thus, more eggs will be incubated during warmer and wetter months. Despite of the previous observation of autumn mating in this species (Koo et al. 2018a), we could not completely exclude the possibility of spring mating at the moment.

Based on our observation, before egg laying, only one instance of feeding was observed for the mother. Decrease in feeding by gravid snakes is partly related to reduced locomotor speed and endurance, which might compromise their ability to catch a live prey (Seigel et al. 1987; Gregory 2009). After oviposition, the female displayed a more active feeding behavior to a maximum of 14 records until release into the wild. It is probably due to the accumulation of lipid reserves in fat bodies, which 
is related to vitellogenesis in females (Girons 1982). Once this takes place, a new breeding cycle begins (Solorzano and Cerdas 1989).

To the best of our knowledge, this is the first study to report the reproductive biology of $S$. chinensis from egg laying to hatching. This study is limited by its sample size. To establish an accurate reproductive activity of $S$. chinensis, it is necessary to analyze large samples in the wild.

\section{Abbreviations}

BW: Body weight; HL: Head length; HW: Head width; SVL: Snout-vent length; TL: Tail length

\section{Acknowledgements}

The work was supported by the research grant of Jeju National University in 2019. We are grateful to the Yeongsan Gang Regional Environmental Office for granting collection permit. We extend our thanks to all whose direct and indirect support empowered us in raising the specimen and preparing the manuscript.

\section{Authors' contributions}

$\mathrm{MB}$ and $\mathrm{YHJ}$ participated in raising the specimen. $\mathrm{MB}$ and YKM drafted the manuscript. SHH and HSO edited the manuscript draft. BSK provided specimen along with technical support. All authors read and approved the final manuscript.

\section{Authors' information}

Not applicable

\section{Availability of data and materials}

The specimen during the current study is available from the corresponding author on reasonable request.

\section{Ethics approval and consent to participate}

Authors receive permission from "Yeongsan Gang Regional Environmental Office" for handling and capturing the specimen, without harm.

\section{Consent for publication}

Not applicable

\section{Competing interests}

The authors declare that they have no competing interests.

\section{Author details}

${ }^{1}$ Faculty of Science Education, Jeju National University, Jeju 6324, South Korea. ${ }^{2}$ Korean National Park Institute of Biodiversity Conservation, Korean National Park Service, Wonju, South Korea. ${ }^{3}$ Shinseong Girls Middle School, Jeju City, Jeju Island, South Korea. ${ }^{4}$ Interdisciplinary Graduate Programme in Advance Convergence Technology and Science, Faculty of Science Education, Jeju National University, Jeju 6324, South Korea.

Received: 23 July 2019 Accepted: 13 January 2020

Published online: 30 January 2020

\section{References}

Clark RW, Schuett GW, Repp RA, Amarello M, Smith CF, Herrmann HW. Mating systems, reproductive success, and sexual selection in secretive species: a case study of the western diamond-backed rattlesnake, Crotalus atrox. PLoS One. 2014; $9:$ e90616.

Dieckmann S, Norval G, Mao JJ. A description of a clutch of the Indo-Chinese rat snake, Ptyas korros (Schlegel, 1837), with notes on an instance of twinning. Herpetol Notes. 2014;7:397-9.

Girons HS. Reproductive cycle of male snakes and their relationship with climate and female reproductive cycle. Herpetologica. 1982;38(1):5-16.

Gregory PT. Northern lights and seasonal sex: the reproductive ecology of coolclimate snakes. Herpetologica. 2009;65:1-3.

Gunther A. Third contribution to our knowledge of reptiles and fishes from the Upper Yangtsze-Kiang. J of Nat Hist. 1889;4:218e229.
Hartmann MT, Marques OAV, Almeida-Santos SM. Reproductive biology of the southern Brazilian pitviper Bothrops neuwiedi pubescens (Serpentes, Viperidae). Amphib-Reptil. 2004;25:77-85.

IUCN. Sibynophis chinensis. The IUCN Red List of Threatened Species; 2014. p. e. T193454A2237835.

Kane D, Gill I, Harding L, Capon J, Franklin M, Servini F, Tapley B, Michales CJ. Captive husbandry and breeding of Gonyosoma boulengeri. Herpetol Bull. 2017:139:7-11.

Kim BS, Oh HS. The distribution and habitat of Bibari snake (Sibynophis collaris Gray) in Jeju Island, Korea. Korean J of Env and Ecol. 2005;19:342-7.

Kim BS, Oh HS. A taxonomic reinvestigation of the collared many-toothed snake Sibynophis collaris Gray (Reptiles: Serpentes: Colubridae) from Jeju Island, Korea. Integr Biosci. 2006;10:121-3.

Koo KS, Kim TW, Yang KS, Oh HS. First observation on the breeding behavior of endangered species, Chinese many-tooth snake, Sibynophis chinensis. J of Asia Pac Biodivers. 2018a;11:305-7.

Koo KS, Park D, Oh HS. Analyzing habitat characteristics and predicting present and future suitable habitats of Sibynophis chinensis based on a climate change scenario. J of Asia Pac Biodivers. 2018b;12:1-6.

Lin LH, Mao F, Chen C, Ji X. Reproductive traits of the gray rat snake Ptyas korros from three geographically distinct populations. Curr Zool. 2012;58:820-7.

Maia DC, Travaglia-Cardoso SR. Oxyrhopus clathratus (Serpentes: Dipsadidae): reproduction and cannibalism. Oecologia Aust. 2017;21(2):197-200.

Marques O, Pizzatto L. Reproductive biology of the false coral snake Oxyrhopus guibei (Colubridae) from southeastern Brazil. Amphib Reptil. 2002;23(4):495504.

MOE. Ministry of Environment Korea, WWT, UNDP/GEF Korea Wetland Project. 2009. Produced in support of the goals of the Ramsar Conservation on Wetlands.

NIBR. Red data book of endangered amphibians and reptiles in Korea; 2011. p. 125

Oh DJ, Han SH, Kim BS, Yang KS, Kim TW, Koo KS, Chang MH, Oh HS, Jung YH. Mitochondrial genome sequence of Sibynophis chinensis (Squamata, Colubridae). Mitochondrial DNA. 2015;26(2):315-6.

Paik NK. Systematic studies on the suborder Serpentes (Reptilia) in Korea. Sungkyunkwan Univ. 1982:51-2 (In Korean).

Paterna A. Reproduction cycle of the eastern egg-eater snake Dasypeltis medic medici (Bianconi, 1859) in captivity. Russ J Herpetol. 2017;24:228-34.

Roff DA. The evolution of life histories: theory and analysis: Chapman and Hall; 1992.

Santoshkumar P, Kannan P. Observations on morphometry, egg size and juveniles of the endemic caenophidian snake Xylophis perroteti (Dumeril, Bibron and Dumeril, 1854) in the Nilgiris, Western Ghats, India. Current Sci. 2016;110(10):1901-3.

Schwartz JM, McCracken GF, Burghardt GM. Multiple paternities in wild populations of the garter snake, Thamnophis sirtalis. Behav Ecol and Sociobiol. 1989;25:269-73.

Seebacher F, Webster MM, James RS, Tallis J, Ward AJW. Morphological differences between habitats are associated with physiological and behavioral trade-offs in stickleback ( Gasterosteus aculeatus ). R Soc Open Sci. 2016;3(6):160316.

Seigel RA, Huggins MM, Ford NB. Reduction in locomotor ability as a cost of reproduction in gravid snakes. Oecologia. 1987;73:481-5.

Solorzano A, Cerdas L. Reproductive biology and distribution of the Terciopelo, Bothrops asper Garman (Serpentes: viperidae) in Costa Rica. Herpetologica. 1989;45(4):444-50.

Whitaker R, Captain A, Ahmed F. Snakes of India: the field guide. Chennai: Draco Books; 2004

\section{Publisher's Note}

Springer Nature remains neutral with regard to jurisdictional claims in published maps and institutional affiliations. 